\title{
HACIA UNA POÉTICA DE LA IMAGEN DEL CHE: DENOTACIÓN Y CONNOTACIONES EN TORNO A LA FOTOGRAFÍA DE ALBERTO KORDA
}

\author{
Juan Esteban Alegría ${ }^{1}$
}

\section{Resumen/Abstract}

Este año se cumplirán 50 años de la caída en combate del Che Guevara. El guerrillero argentino cubano es uno de los personajes centrales en la historia del siglo XX, y su influencia ha sido determinante en innumerables procesos revolucionarios del Continente Americano. Su imagen desaliñada y su típica boina es una representación que está presente en gran parte de la cultura de izquierda y en los imaginarios colectivos de muchas generaciones. Sin duda, en la construcción de tal simbolismo, juega un papel fundamental la famosa fotografía tomada por Alberto Korda. La imagen guarda en sí una serie de significaciones y códigos posibles de interpretar. Nuestra hipótesis en torno a la seducción que transmite esta imagen se basa en la articulación de lo sagrado y la muerte como sus componentes discursivos principales; conceptos que a la vez entroncan con la propia identidad de Latinoamérica. Metodológicamente este trabajo se propone interpretar las particulares de la citada fotografía, en base a una estrategia de investigación de carácter hermenéutico y transdisciplinar.

Palabras claves: imagen, guerrilla, fotografía, icono político, muerte, hermenéutica.

\section{TOWARDS A POETIC OF THE IMAGE OF THE CHE: DENOTATION AND CONNOTATIONS AROUND THE PHOTOGRAPH OF ALBERTO KORDA}

This year marks the 50th anniversary of Che Guevara's fall in combat. The Cuban guerrilla is one of the central figures in the history of the twentieth century, and his influence has been decisive in countless revolutionary processes on the American continent. His scruffy image and typical beret is a representation that is present in much of the culture of the left and in the collective imaginaries of many generations. Undoubtedly, in the construction of such symbolism plays a key role the famous photograph taken by Alberto Korda. The image itself contains a series of meanings and possible codes to interpret. Our hypothesis about the seduction conveyed by this image is based on the articulation of the sacred and death as its main discursive components. Concepts that at the same time connect with the very identity of Latin America. Methodologically, this work intends to interpret the particulars of the photograph, based on a hermeneutic and transdisciplinary research strategy.

\footnotetext{
${ }^{1}$ Universidad Academia de Humanismo Cristiano. E-mail: juanlicuime@ gmail.com
} 
Keywords: image, guerrilla, photograph, political icon, death, hermeneutics.

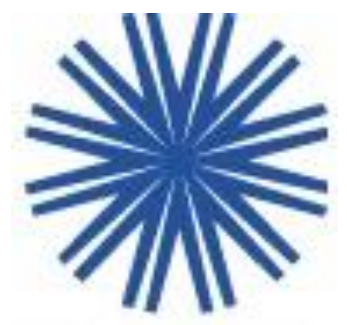

\section{A modo de introducción}

El 9 de octubre de este año se cumplirán 50 años de la caída en combate del Che. El medico argentino cubano y otros guerrilleros fueron capturados y asesinados por el gobierno boliviano siguiendo instrucciones de Washington. Más allá de la lecturas ideológicas y políticas del personaje, su presencia es determinante en la historia de Latinoamérica (García, 2012). La propia Revolución Cubana se puede comprender como la prolongación de las luchas independentistas iniciadas en la isla desde 1868. Desde esta perspectiva, la revolución es el resultado de un proceso de acumulación de condiciones subjetivas y objetivas que generaron causas determinantes para el triunfo de los revolucionarios. La gran cantidad de imágenes que documentan la Revolución Cubana y las propias hazañas del Che, lo han hecho un personaje reconocible en el imaginario simbólico de América; cabe destacar la documentación prolija que realizaron variados fotógrafos de su figura, como el caso de Enrique Meneses, Burt Glinn, René Burri y Osvaldo Salas ${ }^{1}$ entre otros. No obstante, la imagen más famosa es del fotógrafo cubano Alberto Díaz Korda, quien inmortalizó al Che a través de un retrato fotográfico, donde su pelo al viento, su barba descuidada, la boina, la estrella y su mirada, dan cuerpo a una de las fotografías más difundidas del siglo XX (Calzada, 2002:14).

Ahora bien, debemos aclarar que tal fotografía tiene dos momentos determinantes en su construcción, el primero corresponde a la propia fotografía de Korda que pertenece al funeral de las víctimas del Coubre, un carguero francés que transportaba armas compradas a Bélgica por el gobierno cubano (Calzada: 14). Un atentado atribuido a la CIA (marzo de 1960) dejó la trágica cifra de 80 muertos y una cantidad indeterminada de heridos. Korda se encontraba documentando tal acontecimiento cuando logra retratar al Che. Posteriormente, ocurrida la

\footnotetext{
${ }^{1}$ Una de las imágenes más reproducidas del Che corresponde al archivo de Osvaldo Salas, la particular fotografía a la cual nos referimos corresponde a una imagen del guerrillero en una de las tantas concentraciones populares tras la revolución, la fotografía aludida nos muestra al Che de espaldas con su típico tabaco en la boca, el humo y la sinuosa forma de la luz le dan un aura especial a la imagen (para más información ver: Imágenes. Osvaldo Salas. Editorial Oriente. Santiago de Cuba.1990).
} 
muerte de este último en Bolivia (1967) Giangiacomo Faltrinelli, editor milanés y ferviente simpatizante de la Revolución Cubana, publica un cartel con la enigmática fotografía de Korda (Korda aclara no haber recibido ningún dinero por los derechos de la fotografía y de igual manera, sostiene que su error fue regalar una copia de la fotografía a Feltrinelli en uno de sus viajes a Cuba). En tal cartel se habían eliminado detalles que intervenían la propia fotografía, dejando el protagonismo al rostro del guerrillero.

Más allá de la polémica Korda-Feltrinelli, encontramos que la imagen tiene un potencial connotativo que la hace un objeto interesante para estudiar y la permanencia de ésta nos permite formular las siguientes interrogantes ¿cómo podemos interpretar tal fotografía?, ¿es posible que la propia imagen nos revele parte de su enigmático atractivo? Para responder a tales problemáticas, nos situamos desde una metodología hermenéutica, que según Ambrosio Velasco es un método de investigación que buscan comprender un significado especifico por medio de interpretaciones objetivas y comprensivas (2012: .211). El mismo Velasco parafraseando a Dilthey, sostiene que la metodología propia de las ciencias humanas es la comprensión, proceso a través del cual un determinado signo dado previamente a los sentidos puede ser interpretado accediendo a la realidad psíquica que lo refiere. ${ }^{2}$

Concordante con la idea anterior, para Bauman un elemento importante para el análisis hermenéutico radica en la interpretación de lo simbólico:

Los símbolos son objetos que nos remiten a algo diferente de lo que ellos son. Ellos por así decir, tienen un sentido que reside fuera de sí; sólo la persona que conoce el "lazo invisible" que existe entre el símbolo y el objeto al que se aplica, es capaz de captar su sentido. Es así como, por ejemplo, sólo una persona que conozca el código caminero puede comprender que un triángulo blanco con siluetas que caminan dentro de él indica que hay niños que cruzan la ruta (2002: 198)

\footnotetext{
${ }^{2}$ El interpretativismo emergió dentro de las ciencias humanas como una respuesta al intento de desarrollar una ciencia natural de los fenómenos sociales. Como nos aclara María Paz Sandín (Investigación Cualitativa en Educación, 2003) el interpretativismo se posiciona dentro de la confrontación entre las corrientes nomotética (proposición de ley) e ideográfica (conocimiento intensivo, individual o particular) de las ciencias respectivamente. En este contexto, lo nomotético está más bien relacionado con el ámbito físico - natural, donde lo que se buscan son regularidades y leyes. Por otro lado, lo ideográfico se centra en estudios de carácter histórico o de interacción social, donde lo que se busca no son generalidades sino aspectos únicos, individuales y cualitativos.
} 
$\overline{\text { Efectivamente el lazo que los liga a los objetos es permanente y regular en el tiempo. Lo }}$ mismo puede referirse de los síntomas que nos permiten comprender la naturaleza. Los signos en este caso son la réplica de los síntomas, sólo que en los primeros interviene la factura humana. Si bien, la definición anterior nos posiciona más bien desde un ámbito tradicional de la hermenéutica, hoy el discurso contemporáneo de esta última, se construye como un campo complejo y plural (Sandín: 61),donde además emergen diversas concepciones a menudo opuestas de la interpretación. ${ }^{3}$ Particularmente, nuestro trabajo se construye desde una "hermenéutica analógica", que para Nélida Sosa consiste en una hermenéutica abierta y a la vez rigurosa, que se desengancha de una verdad única, en tanto reconoce un límite para enunciar determinadas verdades y enfoques ( Sosa 2007: 33). Se trata entonces de articular un diálogo entre la interpretación subjetiva y objetiva, es una apuesta a una interpretación limítrofe; que se materializa mediante la analogicidad que tiende a universalizar determinados significados dentro de ciertos límites.

La hermenéutica analógica situada desde el horizonte de Latinoamérica, debe considerar el lenguaje no escrito, ya que si bien tenemos una sólida tradición de lo escrito, la noción misma de escritura puede remitir solamente a un tipo de fuentes culturales, de ahí la posibilidad de incorporar otros archivos a nuestra interpretación como mitos, leyendas, dialectos, imágenes, etc.(Arriarán 2007: 15) En este contexto, nuestro trabajo consiste en interpretar hermenéuticamente la fotografía de Korda, tomando a ésta como un texto abierto, que se despliega en un horizonte rico de significaciones, y que al mismo tiempo se relaciona con otros textos alusivos al guerrillero; hablamos de fotografías, cartas, libros , videos etc., que tematizan o tratan la vida de éste. Tal metodología, nos permite plantear como hipótesis de trabajo que la fotografía de Korda funciona como una prolepsis de la propia muerte del Che, es decir, lo que vemos en la imagen es la proyección de un futuro trágico, desventura que rebasa lo individual para situarse desde lo universal, donde la imagen refleja un ethos identitario del ser latinoamericano, donde muerte y sacrificio son elementos recurrentes.

\footnotetext{
${ }^{3}$ Estas concepciones opuestas se pueden resumir básicamente en la hermenéutica de validación, donde existen significados inmutables o inalterables que son el objeto de la interpretación. En segundo lugar, nos encontramos con la hermenéutica crítica, que persigue desentrañar la distorsión de algún significado, para justamente establecer condiciones para la emancipación que haya ocurrido por la tergiversación de éste. En tercer lugar, nos encontramos con la hermenéutica filosófica, que supedita la interpretación a un enfoque dialógico donde la dimensión ontológica tiene una gran relevancia.
} 
Complementan nuestro sustento teórico las respectivas tensiones y análisis que se desprenden desde la semiótica, la filosofía de la fotografía y la cultura visual.

\section{La construcción de una imagen enigmática}

Para el Che la imagen fotográfica no le era indiferente, incluso trabajó como reportero acreditado en más de una ocasión, esto explica el abundante material fotográfico que retrata su vida. Se desprende de lo anterior, que su mítica imagen parece ser el resultado de un proceso de autoconstrucción y autodeterminación visual. En tanto, para analizar el proceso de construcción de la fotografía, debemos establecer una suerte de genealogía o arqueología de la mítica imagen y retroceder en el tiempo hasta los tumultuosos años sesenta. Como ya indicamos, el famoso retrato fue realizado mientras se efectuaba un multitudinario homenaje a las víctimas del Coubre. La fotografía tomada al Che es considerada uno de los mejores retratos foto periodísticos. En el corto Una foto recorre el mundo (1981) de Pedro Chaskel, es posible oír las siguientes palabras de Korda en relación con la famosa imagen "no lo vi hasta que me adelanté para ver la multitud congregada que se extendía a lo largo de kilómetros. Tuve el tiempo justo de hacer una foto horizontal y otra vertical, con un objetivo de 90 milímetros; su aura me impresionó tanto que instintivamente realicé la fotografía." Frente a tales acontecimientos ¿cómo podemos explicar la propia construcción de la imagen?, ¿es posible desde la propia reflexión de la fotografía acercarse a este objetivo?

Desde ya debemos aclarar que pese a los acelerados cambios que han ocurrido en la industria fotográfica, traducibles en la digitalización de sus procesos, el ámbito de lo que denominamos la construcción epistemológica de la fotografía no ha sufrido grandes alteraciones. En este contexto, adquieren sentido las deliberaciones de Phillips Dubois y lo que él denomina el acto fotográfico. Tal cuestión nos lleva a la consideración del principio de la realidad propio de la imagen fotográfica y la relación con su referente (Dubois 1994: 20). En consideración a este problema, Dubois plantea tres aproximaciones en relación con la construcción de la imagen fotográfica: la fotografía como espejo de lo real, la fotografía como transformación de lo real y la fotografía como huella de lo real. La primera categorización remite a la mímesis, la segunda a la deconstrucción y la tercera al índex ¿Pero qué consideraciones 
implican cada categorización en correspondencia con la problemática del referente materializada en la imagen del guerrillero?

Para el autor del Acto Fotográfico, la fotografía como espejo de lo real centra su atención en la verosimilitud, en la cual las nociones de semejanza y realidad se superponen como espejo del mundo (Dubois 1994: 51). Aquí la fotografía adquiere prioritariamente una función documental, que procura evidencia de la naturaleza. Por otro lado, la fotografía como transformación de lo real se aleja sustantivamente de la verosimilitud y la semejanza; ésta más bien se encarga de poner en cuestión la clásica noción de mímesis. Tal enfoque nos plantea que toda fotografía es evidentemente codificada desde diferentes posiciones: técnica, cultural, estética, etc. La tercera posición se determina a partir de la contigüidad física del signo con su referente. (Dubois 1994: 42) Tal concepción se distingue de las anteriores porque implica que la imagen indicial se construye por la acción de cercanía de su referente, es decir la imagen se refiere a su objeto no tanto por la similitud sino por una especie de conexión existencial; el propio Dubois aclara esta cuestión:

Ya se ha mencionado el principio básico de la conexión física entre la imagen foto y el referente que ella denota: es todo lo que la convierte en huella. La consecuencia de este estado de hecho es que la imagen indicial únicamente remite a un solo referente determinado: el mismo que ha causado y del cual es resultado físico y químico. (Duboi 1994: .50).

La singularidad especial de esta relación comporta el poder de designación que adquiere la imagen fotográfica. Haciendo alusión a Barthes, Dubois señala que siempre la fotografía gravita entorno al "vean”, de ahí su fuerte carga testimonial. (Dubois 1994: 50). Por lo demás, esta acción permite darle una relevancia especial al contexto de enunciación de la fotografía. Foucaultianamente entendemos aquí el enunciado como un elemento irreductible de un discurso que no es susceptible de descomposición y que es capaz de ingresar a un juego de relaciones con otros enunciados. (Foucault 2006: 67). Esto supone también la determinación de "un régimen de materialidad irrepetible" para designar las condiciones de singularidad de la enunciación. Desde esta posición, el contexto que da origen a cualquier fotografía se relaciona con espacio, emotividad, ritualidad, etc. Tales características son claves a nuestro juicio al momento de pensar las condiciones que dan corpus a la imagen mítica imagen del 
Che. Como señala Dubois la imagen foto se torna inseparable del acto que la funda, por tanto, hablamos de una fotografía huella.

Por otro lado, Flusser (1990: 11) nos señala que el significado de la imagen- foto es la síntesis de dos intensiones: la manifiesta en la imagen misma y la exteriorizada en el observador. Por tanto, la imagen fotográfica rebasa la denotación inscribiéndose en un registro connotativo, susceptible de infinidad de interpretaciones. (Flusser, p. 11). El mismo autor nos plantea el significado de la imagen como mediación entre el hombre y el mundo. Complemento de lo anterior, son las expresiones de Barthes, para quien lo determinante en la naturaleza de la fotografía es la pose (Barthes 1990: 138), que podemos definir como una "intensión de lectura", acción que puede explicarse como el instante (por breve que sea) en que el ojo queda prendido de su referente, implicando posteriormente la evidencia de tal fijación en la fotografía. Esta presencia del pasado que atestigua algo real, tiene su origen para el semiólogo francés como arte de la persona y su identidad (Barthes, p.140).

Es así como la imagen del guerrillero atestigua un "había sido", traducible en una atmósfera de recogimiento, tensión e imperturbabilidad. Determinantes para contextualizar lo anterior, son las nociones de studium y punctum para desglosar el interés que suscita la imagen. Por studium entendemos cierta clasificación o categorización de las fotografías, y por punctum Barthes ejemplifica la acción de un pinchazo o corte que direcciona el interés en determinada fotografía ${ }^{4}$. De esta forma, mientras el studium no sea atravesado por un detalle o marca se convertirá en una fotografía sin interés. Por el contrario, la fotografía que nos punza es una copresencia entre studium y punctum, además a menudo lo que nos punza es un detalle u objeto singular de la imagen, ¿qué es entonces lo que nos punza en el retrato del Che Guevara? Interpretando al mismo Korda, lo que nos punza es su enigmática mirada: mezcla de dolor y determinación.

\footnotetext{
${ }^{4}$ Por studium Barthes entiende también el interés por determinadas fotografías que originan una extensión o campo, es decir el studium da cuenta de la afición por cierta clase de imágenes, donde es el propio sujeto el que actúa comprometiéndose en tal proceso. Por el contrario, el punctum es el que punza al sujeto, es este último el que sale al encuentro del individuo tensionando el campo o espacio de la mirada.
} 
En definitiva, nos encontramos con un sujeto que parece querer asumir en su propia persona el momento trágico en el cual se despliega la tragedia del Coubre. La muerte comienza a configurar el derrotero del médico argentino; es aquí donde el concepto de híper-amnesia desarrollado por Octavio Paz adquiere sentido al momento de enfrentarnos a la fotografía. Para el pensador mexicano, la hipermnesia (Gissi 2002: 142) se define como lo contrario de amnesia, en la híper-amnesia el pasado se agiganta y queda como un trauma siempre presente. El trauma de la violencia inoculada por los españoles en la conquista es precisamente ese acto destructivo y ligado a la muerte que es parte consustancial de nuestra identidad como latinoamericanos. Tal acontecimiento traumático revive siempre en cada tragedia, recordándonos esa ligazón con lo destructivo y la muerte, que da cuenta de nuestro pasado, presente y futuro.

\section{Denotación y connotación en la imagen del Che Guevara}

Una difícil empresa resulta analizar la fotografía del Che en función de sus rasgos denotativos (objetivos). La importante carga ideológica y la multiplicidad de sus reproducciones instalan una serie de obstáculos al momento de referir las características denotativas de la citada imagen. Al retroceder en el tiempo e instalar una especie de corte sincrónico, nos encontramos en el año 1960, con la figura de uno de los principales líderes de la Revolución Cubana. La fotografía de Korda retrata a un destacado militar que ostenta el grado de comandante $^{5}$, que además representa la instalación de un nuevo proyecto político en América. Sin embargo, como se sostuvimos anteriormente, la fotografía no se difundió hasta la trágica muerte del Che, ocurrida en 1967 en un apartado rancho de la Higuera en Bolivia.

\footnotetext{
${ }^{5}$ Significativo para entender las claves en la construcción de mítica imagen del Che, es el episodio cuando es nombrado comandante; es así como en variados textos y libros se cita este hecho como decisivo para el líder guerrillero. El suceso se remonta a los primeros días de julio de 1957, en el preámbulo de las conmemoraciones de un nuevo aniversario del asalto al Cuartel Moncada, y en el contexto de la firma de una carta de apoyo a Frank País, cuyo hermano había asesinado por la dictadura de Batista. En plena campaña militar la mayoría de los miembros del incipiente Ejército Rebelde firma la misiva. Al momento de detallar la identificación de quienes dirigen las dos columnas, Fidel expresa su deseo de designar con el grado de comandante al Che, hasta ahora encargado de una de las columnas. La expresión "ponle comandante" ha quedado registrada como un gesto de confianza de Fidel hacia el Che que tiene a su vez un componente afectivo y de camarería; el gesto no es menor, ya que el médico argentino cubano se convertirá en el primer comandante después de Fidel, que recibe ese grado por parte del Ejército Rebelde (ver El Che en Combate de Antonio Núñez). El propio Che rememora tal acontecimiento en "Pasajes de la Guerra Revolucionaria", aludiendo a la dosis de vanidad que le provocó este nombramiento y la pequeña estrella que simbólicamente le fue entregada, siendo esta última; uno de los elementos característicos que formaran parte de su ideario simbólico.
} 
El tiempo que media entre la fotografía (1960) y su definitiva publicación (1967), no es un tema menor. En el transcurso de esos siete años la figura del Che alcanza una enorme importancia en Cuba y en el resto del planeta. A esto se agregan los numerosos viajes que realizó por el mundo, llevando la impronta de la Revolución Cubana. Incontables son los lugares que recorre: Praga, la ex Unión Soviética, China, Corea, Berlín, Uruguay, Checoslovaquia, Argelia, Ginebra, Nueva York, Malí, el Congo, Ghana, Guinea, Dohomey, Paris, Tanzania, el Cairo, el Congo, y Bolivia entre otros territorios. La importancia de estos viajes radica en que el Che Guevara viaja aquí como un héroe, su figura y prestancia le valen un reconocimiento mundial, así es reconocido en los distintos lugares que visita (Cupull y González, 1997).

A lo anterior, se suma una inmensa cantidad de funciones y cargos desempeñados: Comandante del Ejército Rebelde (1957), el otorgamiento de la nacionalidad cubana (1959), condecoración en Gaza con la orden del Gran Libertador de los oprimidos (1959), Presidente del Banco Nacional de Cuba (1957), condecoración por el Gobierno Checo con la Orden del León Blanco (1960), Ministro de industrias (1961), condecoración por el gobierno de Brasil (1961), presidente de la delegación cubana en la Conferencia Mundial sobre Comercio y Desarrollo (1964). A esto se agregan una infinidad de discursos, seminarios y conferencias en las cuales hacía emerger su especial carisma. Con todos estos antecedentes, podemos sostener que la imagen del guerrillero forma parte de un proceso de autoconstrucción, acción que se acrecienta con su trágica muerte. En este sentido, la fotografía de Korda sólo alcanza su efectivo valor una vez conocida la noticia de la muerte del guerrillero. Constatamos que existe una especie de simbiosis entre dos tiempos cronológicos diferentes en su vida: por una parte, está el preciso momento en que se toma la famosa fotografía, ocasión donde él asiste a la conmemoración de la tragedia del Coubre, un hecho directamente ligado con la muerte. Por otro lado, su muerte es lo que permite que su imagen sea difundida: asistimos a dos momentos trágicos, en los cuales la caída ocupa un lugar central, articulándose el binomio muerte-expiación. 
Como ya hemos señalado, lo que denotamos en la fotografía de Korda es el rostro de un guerrillero desaliñado y la resonancia de una estrella que remata en su boina, elementos que constituyen los significantes de la fotografía. Los significados simbólicos de todos estos elementos encadenados corresponden a la emergencia de la figura del líder revolucionario que, por cierto, pasará a la historia con el apelativo de Che, apodo que tiene una significación importante en el desarrollo y surgimiento del mito del guerrillero heroico. Al respecto hay que recordar que tal interjección característica del hablar en argentina fue el sobrenombre con el cual designaron al guerrillero los combatientes cubanos. Más aún al analizar una serie de cartas del Che entre los años 1953 y 1956, estas son firmadas simplemente con su nombre Ernesto. Posteriormente, el mismo firmará sus escritos con el apelativo del Che. En este punto, resulta interesante recordar un extracto de la carta de despedida de este último a Fidel:

Otras tierras del mundo reclaman el concurso de mis esfuerzos. Yo puedo hacer lo que está negado por tu responsabilidad al frente de cuba y llegó la hora de separarnos... Tendría muchas cosas que decirte a ti y a nuestro pueblo, pero siempre siento que son innecesarias, las palabras no pueden expresar lo que quisiera, y no vale la pena emborronar cuartillas. Hasta la victoria siempre. ¡Patria o Muerte! Te abraza con todo fervor revolucionario, CHE (Salas, 1991: 7).

En este punto, Ernesto Guevara asume su apelativo del "Che" como conciencia ontológica de su existencia. Y es aquí, donde quizás comienza la construcción de su propio mito. En esta perspectiva, la publicación por parte de Feltrinelli de la comentada fotografía es sólo la materialización del mito que ya se había construido.

\section{Connotación}

La fotografía del Che se ha transformado en un símbolo con una fuerte raíz connotativa. Para los lectores que tienen una ideología afín a nuestro personaje, éste representa una especie de Marx contemporáneo; en él se trasuntan las figuras de destacados revolucionarios: Blanqui, Bakunin, Durruti, Danton, Marat, etc. Por otra parte, el público menos sobre ideologizado encuentra en su figura un símbolo de rebeldía contra el establishment o las tradiciones de una determinada época. La figura del guerrillero es transversal generacionalmente y sus simpatizantes pueden ser jóvenes adolescentes, como adultos o ancianos. Su imagen se puede 
encontrar en Asia, África o Europa; pero es en Latinoamérica, donde su figura alcanza connotaciones particulares.

Pero de qué hablamos cuando nos referimos a la connotación ¿qué significa específicamente que un determinado símbolo sea connotativo? En "La Connotación" (1983), Kerbrat nos aclara desde la lingüística la dificultad y las distintas bifurcaciones que encierra el concepto. En sus comienzos desde la lógica y la filosofía por connotación se entendía la actividad de comprensión de un enunciado o término. Sin embargo, la linguística y la semiología se alejan de la idea de comprensión y proponen el fenómeno de la connotación como el conjunto valorativo (secundarios, periféricos) de un término o en otras palabras los valores distintivos que arroga la propia acción de la denotación (Kerbrat 1983: 16). Como complemento de esta definición, la autora nos señala que la connotación se manifiesta cuando se comprueba la aparición de valores semánticos con un estatuto especial, que se alejan progresivamente del valor referencial del objeto significado. Es así como podemos tener diferentes niveles de connotación, siendo en este caso el nivel físico el que tiene más ganancia para nuestro análisis, proceso que se refiere a la connotación del lenguaje verbal, el lenguaje visual y el lenguaje musical (Kerbrat: 27). Hablamos entonces de la riqueza connotativa de la fotografía de Korda, al momento de pensar la articulación de la red semántica que emerge en la imagen y que permite ligar espacios tan diversos como son el marxismo, la religiosidad popular, la contracultura, la rebelión juvenil, etc.

En este contexto, la fotografía que hemos tomado como objeto de estudio, connota y dialoga con toda una tradición del fotoperiodismo en Latinoamérica que, en la búsqueda de la fuente directa de la noticia o el conflicto, se transformó en un importante medio para registrar las primeras revoluciones modernas en nuestro continente ${ }^{6}$. Es así como la labor desarrollada

\footnotetext{
${ }^{6}$ En El uso de las imágenes, Gombrich (2003) repasa en forma meticulosa los uso que han tenido las imágenes a través del tiempo. Publicidad, decoración, religiosidad etc., son muestra de los diversos campos que reclaman su uso, siendo también la ilustración de los procesos revolucionarios una fuente inagotable para estas. Particularmente, la Revolución francesa fue pionera en la explotación de recursos representacionales para resituar y proyectar a través de las imágenes una nueva época. Resultan atractivas aquí las ilustraciones de la libertad y la razón, que generalmente se dan corpus a través de bellas mujeres o figuras aladas. La alusión a este texto no es gratuita, ya que en lo sustancial en él se desarrolla la tesis de la imposibilidad de pensar sin imágenes, y más aún cuando nos encontramos en la efervescencia de procesos revolucionarios; de ahí que toda revolución se materializa como realidad simbólica por medio de las imágenes que puede hacer circular.
} 
por el fotoperiodismo en el México revolucionario es fundamental para apreciar los diferentes desplazamientos de la discursividad de la imagen del guerrillero y la posterior conformación de la imagen heroica del Che. Por cierto, la fusión entre imagen y texto como campo discursivo permitió que los sectores históricamente postergados en México visibilizarse como actores políticos y elaborando un discurso propio. Retomamos aquí el discurso, como un conjunto de enunciados que guardan cierta frecuencia, proceso que Foucault determina de la siguiente manera:

El enunciado es siempre un acontecimiento que ni la lengua ni el sentido pueden agotar por completo. Acontecimiento extraño, indudablemente: en primer lugar, porque esté ligado por una parte a un gesto de escritura o a la articulación de una palabra, pero que por otra parte se abre a sí mismo una existencia remanente en el campo de una memoria, o en la materialidad de los manuscritos, de libros y de cualquier otra forma de conservación (Foucault 1978: 46).

Debemos contemplar en estas circunstancias que el discurso de los emergentes sectores populares de México se produce desde el particular espacio del fotoperiodismo. Es gracias a la fotografía que el movimiento liderado por Zapata emerge con especial fuerza en la sociedad. A través de las numerosas fotografías de Villa y Zapata, se instala en el inconsciente de la sociedad la imagen del ejército guerrillero. Si bien las fotografías que llegan al público son escogidas y seleccionadas en función de una política editorial y diagramada de acuerdo con un discurso institucional, el espectador puede establecer su propio juicio al contemplar estas imágenes. En este sentido, por la peculiar capacidad mimética de la fotografía, existe un grado de objetividad inherente a la imagen exhibida. Fundamental en el registro y archivo de este proceso es la Agencia Casasola. Agustín Casasola fue uno de los fotógrafos de prensa más destacados del siglo XX en México (Escorza 2010), particularmente son muy apreciados los registros sobre el cadáver de Emiliano Zapata (1919) y el retrato de Augusto Cesar Sandino (1929).

En este sentido, la imagen del Che hay que interpretarla como parte de esta tradición del fotoperiodismo, donde tiene un lugar destacado la figura del líder o héroe popular. Al mismo tiempo, la propia imagen la podemos comprender connotativamente situándola a la par con 
la profusión de textos y conceptualizaciones que tematizan la vida del Che o incluso con los propios escritos de este último. En tanto, si volvemos nuevamente nuestra mirada al retrato de Korda ¿qué es lo que vemos?, ¿en qué clave o dimensión se nos revela su mirada? En función de encontrar respuestas a estas interrogantes, hallamos en "La Guerra de Guerrillas" la idea recurrente del guerrillero como reformador social y ante la pregunta ¿por qué lucha el guerrillero? el propio Guevara responde:

Tenemos que llegar a la conclusión inevitable de que el guerrillero es un reformador social, que empuña las armas encarnando a la protesta airada del pueblo contra sus opresores y que lucha por cambiar el régimen social que mantiene a todos sus hermanos desarmados en el oprobio y la miseria (Guevara, 2007a: 17).

Ciertamente, en tal frase comprobamos la identificación que adquiere el guerrillero y su fusión con los actores activos del mundo social, fusión que en determinado momento debe materializarse en la lucha directa contra el enemigo, situación que podemos contemplar en Alegría del Pío, primer combate entre los revolucionarios y el ejército de Batista:

Quizá ésa fue la primera vez que tuve planteado prácticamente ante mí el dilema de mí dedicación a la medicina a mi deber de soldado revolucionario. Tenía delante una mochila de medicamentos y una caja de balas, las dos eran mucho peso para transportarlas juntas; tomé la caja de balas, dejando la mochila para cruzar el claro que me separaba de las cañas. Recuerdo perfectamente a Faustino Pérez, de rodillas en la guardarraya, disparando su pistola ametralladora (Guevara, 2007b: 11).

Nos encontramos con la evocación de la figura de un reformador social, que al mismo tiempo se convierte en la vanguardia del pueblo y que toma las armas en función de un proyecto liberador. A lo anterior, se añade la superioridad moral que declama el papel del guerrillero, adquiriendo en sí las propiedades de los grandes humanistas de la historia. Simbólicamente estamos en presencia de la figura del héroe, figura arquetípica que según Jung (1984: 109) comparte un modelo universal y que, más allá de las diferencias que encontramos en diferentes culturas, podemos identificar en las siguientes características: su lucha contra el mal, su caída y sacrificio. Un episodio que retrata en forma anecdótica las connotaciones especiales que se fue forjando el Che durante su dirección del ejército guerrillero, es la 
voladura del puente Falcón (en el contexto de la planificación de la toma de Santa Clara). La Columna 8 bajó las órdenes del Che ejecutó tal acción, sin embargo, el puente no sucumbió inmediatamente:

\begin{abstract}
Sobre la voladura del puente Falcón se extendió, en forma de broma, una anécdota: el Che, al enterarse de tal acción, se acercó al puente que no se había terminado de caer, dio un puntapié e inmediatamente se cayó. Eso basto para que, en son de burla, los combatientes digieran que el Che lo había tumbado de una patada. por cierto, hay una foto donde se encuentra el Che contemplando el puente derribado (March, 2011, p.51).
\end{abstract}

Los episodios que hablan de naturaleza heroica de él son numerosos. Basta recordar cómo la afección de su enfermedad no fue impedimento para sus metas y logros. En definitiva, nos encontramos con un personaje que materializa un ethos que para nosotros se plasma como punto de inflexión en la citada fotografía de Korda. Tal acción nos retrotrae al año 1960, un año simbólicamente potente que presenta la dualidad entre vida y muerte. Es el año en que Aleida March compañera del Che, recibe la noticia de su primer embarazo, y, por otra parte, es el año de la desventura del Coubre, tragedia desde donde surgirá la clásica consigna ¡patria o muerte!, como elemento del pathos de la propia revolución. Hablamos entonces de la ligazón de vida y muerte como un elemento recurrente para pensar la propia dimensión simbólica del guerrillero, donde los elementos sacrificiales son nuevamente determinantes.

En definitiva, nos encontramos con una imagen rica en connotaciones y por lo mismo, ha tenido diversas interpretaciones. Precisamente hoy en día, en el lugar donde el Che encontró trágica muerte, se le venera con el apelativo de San Ernesto de la Higuera. Éste ha pasado a formar parte del panteón de los numerosos santos que reciben las peticiones del pueblo, ¿cómo explicarse tal proceso? Sin duda, por la misma construcción connotativa de la imagen, las respuestas pueden girar en varias direcciones. No obstante, la réplica a tal interrogante se encuentra en los mismos pobladores de la Higuera y Valle grande (Prendes, 2006), son ellos los que han construido una particular lectura de la figura del guerrillero. El culto generado frente a la imagen y que se materializa en la fotografía de Korda, se ha propagado por todas las localidades cercanas al sitio donde este murió. Parte de este culto, se puede explicar por las connotaciones con el Cristo crucificado que genera la imagen. En cierto sentido, nos 
encontramos con dos personajes que en sus respectivos contextos históricos realizaron actividades subversivas contra los poderes de turno:

Mateo y Marcos nos informaron, además, que Jesús fue crucificado entre dos "ladrones" (Mt 27,38; Mc 15,27). Ahora bien, ésa era la denominación despectiva que las autoridades daban a los rebeldes e insurrectos, como puede verse cotejando "Barrabás era ladrón ...el cual había sido encarcelado por un levantamiento y homicidio sucedido en la ciudad" (Lc23,19). Resulta que Jesús fue crucificado entre dos rebeldes y en fila con ellos, sólo que con mayores méritos que ellos, por eso lo pusieron en medio y con letrero de su delito. Sobre Jesús de Nazaret no hay ni un solo hecho histórico que sea más comprobable que éste: que hizo actividad política revolucionaria (Porfirio 1998: 78).

En este contexto, los pobladores de la Higuera vieron en la figura desvalida de Guevara la encarnación de un nuevo Cristo: perseguido, traicionado y asesinado por luchar por sus ideales. Fundamental en términos connotativos, resultan la afirmación realizada por el crítico de arte inglés John Berger (citado por Pierre Kalfon, en la obra "Che una Leyenda de Nuestro Siglo”), quien fue el primero que llamó la atención sobre la extraña analogía entre las fotos del cadáver del Che y algunas famosas pinturas de la Historia del Arte, específicamente: $L a$ Lección de Anatomía de Rembrandt (1632). Al contemplar estas imágenes, se produce una peculiar relación sintagmática, al parecer las imágenes establecen cierto diálogo, pues hablarían de hechos similares: muerte y sacrificio.

En lo referido a las connotaciones con la Lección de Anatomía de Rembrandt, resulta interesante recalcar el carácter teatral que tienen las composiciones del pintor holandés, donde los personajes se subordinan al modelo, y donde, además, las manos tienen un significado trascendental: éstas representan al tacto como complemento de los demás sentidos. El tacto se convierte entonces en un elemento primordial para establecer la relación con el mundo. De la misma manera, la escena donde está depositado el cadáver del Che resulta altamente teatral, como si a propósito se hubieran dispuestos los elementos subordinados al cuerpo inerte del guerrillero, la analogía con la pintura de Rembrandt es inevitable. 
No obstante, las connotaciones no terminan en las pinturas de Rembrandt, por el contrario, podemos establecer una infinita red de indicadores connotativos. Por ejemplo, la pintura del Giotto El Llanto por Cristo Muerto (1305-1306), también muestra significativas analogías con la escenografía que da cobijo al cuerpo del guerrillero. Otro ejemplo lo constituye el cuadro de Caravaggio La muerte de la Virgen (1606), en el cual, al igual que Cristo; se aprecia el cuerpo acompañado de un sequito de delirantes espectadores. También podríamos agregar a esta cadena connotativa, la relación que podemos establecer entre el primer retrato fotográfico en Latinoamérica, que corresponde míticamente a la Virgen de Guadalupe y el propio retrato del Che, si tensionamos los espacios enunciativos de tales imágenes encontraremos muchas coincidencias (Alegría, 2011).

Ahora bien, después de constatar la profusión de imágenes que dialogan con la iconografía guevarista, podemos preguntar ¿cómo podemos explicar su riqueza connotativa? Obviamente la respuesta no se encuentra en la superficie del fenómeno, sino que habría que plantear la construcción de esta peculiar iconografía, en función de una arquitectura interior, donde lo sacrificial adquiere un protagonismo relevante. A lo anterior, se agrega la muerte en su sentido simbólico como característica de la construcción del ícono político en Latinoamérica. Al parecer asistimos a una constante lectura de tanatografías, en las cuales, el rostro inerte del Che funciona como un juego de espejos; en los cuales se exhibe la constante presencia de tánatos en la conformación de nuestras identidades. Se trata de una especie de reflexión especular, en ésta los rayos de luz incidente en una superficie lisa provocan el denominado fenómeno de la reflexión, de ahí que el rostro enigmático del Che refleja nuestra condición trágica de ciudadanos latinoamericanos. Al mismo tiempo, la imagen de Korda enuncia una cadena semántica, donde cada fotografía del Che articula un red-secuencial que termina o comienza con aquella fotografía tomada en 1960. Por otro lado, sí relacionamos las numerosas fotografías que retratan al Che con la lingüística, éstas funcionan como verdaderas isotopías ${ }^{7}$, como nos aclara Kerbrat:

Los hechos de connotación son en general demasiado tímidos como para poder presentarse en forma aislada; tienden, por lo tanto,

\footnotetext{
${ }^{7}$ Por isotopía se entiende toda una secuencia discursiva provista de cierta coherencia sintagmática, que se articulan gracias a la ocurrencia de unidades de expresión y /o contenido.
} 
organizarse en redes y a constituir isotopías; el efecto de sentido surge precisamente, de esta convergencia de unidades connotativamente homogéneas (Orecchioni, 1983, p.200).

Estas isotopías no se organizan de un modo estructurado, se tratan más bien de unidades que funcionan como conjuntos no ordenados, que tienen, sin embargo, relaciones sintagmáticas, y que se ordenan en función de elementos singulares. Lo que queremos decir entonces es que el famoso retrato de Korda funciona como un centro mediador, desde donde adquieren sentido y visibilidad el acopio de material fotográfico y visual entorno al guerrillero.

\section{Conclusión}

Ad portas de las conmemoraciones del 50 aniversario de la muerte del Che en Bolivia (19281967), la imagen recurrente que acompañará la serie de ritualidades de tal acontecimiento será, sin duda, la fotografía de Alberto Korda. La hipótesis que explica la persistencia de la imagen se basa en la condición de sacralidad que tiene esta última, otorgándole una fuerte carga connotativa; connotación que por lo demás forma parte de la propia arquitectura simbólica de la imagen. Desde el espacio teórico que Flusser denomina filosofía de la fotografía, constatamos que la imagen se justifica a sí misma, en función de sobrepasar la individualidad del personaje retratado y convertirse en un símbolo universal. Además, la imagen resultante posterior al disparador de la cámara está constituida por toda una carga emocional, sensitiva, y contextual que rodea a la misma imagen y que es traducible en una rica red de conceptualizaciones.

Desde esta perspectiva, lo que interpretamos de la imagen es su dimensión de sacralidad y muerte, que se ejemplifican además por los propios signos que recorren la fotografía. En tal sentido, ésta forma parte de nuestro imaginario de latinoamericanos, porque atestigua la enunciación de un destino trágico, que es permeabilizado como imagen. En una clave de significación más profunda, la fotografía nos permite preguntarnos por la dificultad y la tragedia que acompaña siempre los esfuerzos empeñados en lograr niveles de justica en nuestras naciones. En este plano, el concepto de híper-amnesia que recogemos de Octavio Paz, confirma acertadamente lo que la imagen logra comunicar; es decir la fotografía es una prolepsis de un destino individual trágico, que al mismo tiempo encierra los dolores de todo 
un continente. Nos encontramos con una imagen poética, en tanto, logra transmitir un conjunto de afecciones que están más allá de las consideraciones de la fotografía, y que tiene un conjunto de desplazamientos rituales, culturales, simbólicos, políticos, etc., de insospechados alcances para preguntarnos por nuestra identidad.

Por último, resulta destacable el rescate que han hecho Deleuze y Guattari de la guerrilla como dispositivo simbólico, tal reivindicación se debe principalmente a la naturaleza nómade y antiestatal que deja trasuntar ésta. El carácter rizomático de la misma guerrilla nos contextualiza el significado de una organización que apuesta a la diferencia y dislocación de los sentidos. ¿Pero qué papel juega la imagen del Che en esta cuestión?, respondemos que a todas luces la imagen tiene un rol central, ya que es en ella donde confluyen los desplazamientos connotativos de diferentes sectores, en definitiva, es una imagen nómade e itinerante, y que apuesta siempre a la fugacidad de su propia identificación. 

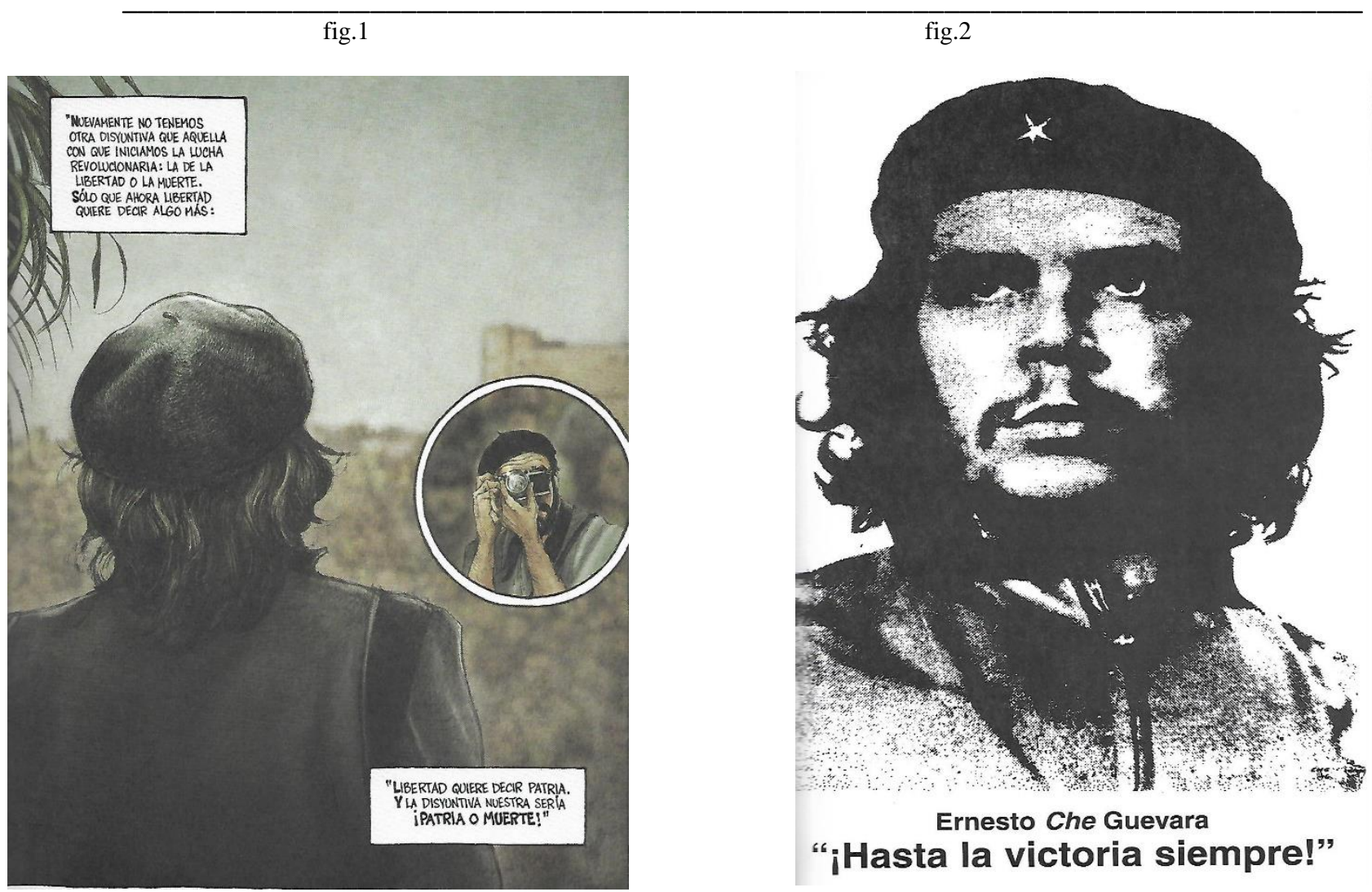

Fig.1- Escena del instante que Korda registra la participación del Che en el homenaje a las víctimas del ataque al Coubre (Novela Gráfica, "Che: una vida revolucionaria”).

Fig.2- Póster del guerrillero Heroico (Che Guevara, Isidoro Calzada)

Referencias bibliográficas

Albano S (2006), Michel Foucault: Glosario Epistemológico. Buenos Aires: Editorial Quadrata.

Alegría J (2011), El Che travestido: Genealogía del ícono político en Latinoamérica. Editorial Académica Española. España.

Bauman Z (2002), La hermenéutica y Las Ciencias Sociales. Buenos Aires. Nueva Visión. 
Barthes R (1990), La Cámara Lúcida. Barcelona. Paidós Comunicación.

Calzada I (2002), Che Guevara. España. Ediciones Status.

Cupull A \& González F. (1997), Ciudadano del Mundo. Ciudad de la Habana. Editorial Capitán San Luis.

Guattari F. \& Rolnik S. (2015). Micropolítica, Cartografías del deseo. Buenos Aires. Fondo Editorial Casa de las Américas.

Guevara E. (2007), La guerra de Guerrillas. Bogotá. Editorial Ocean Sur. (2007). Pasajes de la Guerra Revolucionaria. Bogotá. Ocean Sur.

Escorza D. (2010), Casasola: el fotógrafo y su colección. Madrid. La fábrica editorial.

Fucault M. (1978), La Arqueología del Saber. México. Siglo Veintiuno Editores.

Flusser V. (1990), Hacia una Filosofía de la Fotografía. México. Editorial Trillas

García M. (2012), Revolución Cubana: Historia, conflictos y desafíos. Concepción. Ediciones Escaparate.

Gissi J. (2002), Psicología e Identidad Latinoamericana. Santiago de Chile. Ediciones Universidad Católica de Chile.

Gombrich H. (2003), EL uso de las imágenes: Estudios sobre la función social del arte y la comunicación visual. México. Fondo de Cultura Económica.

Jung C. (1984), El hombre y sus símbolos. Madrid. Luis de Caralt Editor, S.A.

Kerbrat C. (1983), La Connotación. Buenos Aires. Librería Hachette S.A.

March A. (2011), Evocación: mi vida al lado del Che. México. Ocean Sur.

Núñez J. (2014), El Che en Combate: La campaña guerrillera en Cuba Central. La Habana. Edición Rosario.

Dubois P. (1994), El acto fotográfico. Barcelona: Paidós Comunicación.

Porfirio J. (1988), Comunismo en la Biblia. México. Ediciones Siglo Veintiuno.

Salas O. (1991), Imágenes. Santiago de Cuba. Editorial Oriente. 
Sandín M. P. (2003), Investigación Cualitativa en Educación: Fundamentos y tradiciones. España. Universidad de Barcelona.

Sosa N. (2007) "Hermenéutica crítica y analógica" en Samuel Arriarán (coor.) La hermenéutica en América Latina: analogía y Barroco. México, D.F: Editorial Ítaca.

Velasco A. "Hermenéutica y Ciencias Sociales", en Enrique de la Garza, Gustavo Leyna (eds.). Tratado de Metodología de Ciencias Sociales: Perspectivas Sociales. México: Fondo de Cultura Económica.

Material web

Pedro Chaskel (Una foto recorre el mundo) [ archivo video] Cuba, 1981. Duración 12 minutos. Recuperado de https://www.youtube.com/watch?v=qWEmoooK7qQ.

Isabel Santos (San Ernesto de la Higuera) [ archivo video] (Cuba, 2006). Duración 47 minutos. Recuperado de https://www.youtube.com/watch?v=MusFDpqny A\&t=1312s. 